\title{
EFFICACY OF THE PERIOPERATIVE VENLAFAXINE VERSUS PREINCISIONAL PARAVERTEBRAL BLOCK ON POSTMASTECTOMY PAIN SYNDROME: RANDOMIZED TRIAL
}

\author{
Samia A. El-Wakeel,Neveen M. El-Aassar,Tamer S.M. Soliman and Reham M.Aamer \\ Department of Anesthesia and Surgical Intensive Care, \\ Faculty of Medicine, Zagazig University.
}

\begin{abstract}
Background:Postmastectomy pain syndrome (PMPS) is a neuropathic pain syndrome that is known to develop after breast surgery.There is evidence that analgesic treatment in advance of surgical trauma (preemptive analgesia) may be more effective in controlling pain than administering analgesic therapy in response to pain after surgery.We compared the efficacy of venlafaxine, paravertebral block (PVB), and both of them on acute and chronic pain over 12 months following breast cancer surgery to evaluate which has better effect.

Subjects and methods:The study was carried out on 60 patients scheduled for radical mastectomy with axillary dissection. They were randomized into 3 groups to receive extended release venlafaxine $37.5 \mathrm{mg} / \mathrm{d}$ for 2 weeks starting the nightprior to surgery, PVB with $0.5 \%$ bupivacaine $1.5 \mathrm{mg} / \mathrm{kg}$ at $\mathrm{T} 3$ before general anesthesia,or both of them.Pain scores were recorded by visual analog scale (VAS) at rest and with movement at $0,6,12$ and 24 hours on the first postoperative day with comparison of the analgesic requirements between the 3 groups, and then at 1,3,6,9, and 12 months.Complications were recorded in the 3 groups.

Results:The VAS scores were higher in venlafaxine group versus PVB and combined groups at $0,6,12$, and 24 hours postoperative either during restorwith movement with significant increase in the total morphine consumption invenlafaxine group compared to the other 2 groups .At $1,3,6,9$, and 12 months there was no difference in pain scores during rest, while with movement the pain scores were significantly reduced in PVB and combined groups in comparison with venlafaxine group at 9 and 12 months.No significant differences were noted

Among the groups with regard to edema or rate of complication.

Conclusion:Preincisional PVB with $0.5 \%$ bupivacaine $1.5 \mathrm{mg} / \mathrm{kg}$ at T3 before general anesthesia provides good acute postoperative pain relief than venlafaxine $37.5 \mathrm{mg} / \mathrm{d}$ for 2 weeks starting the night prior to surgery.The efficacy of venlafaxine, PVB, or combination of them are similar after 6 months in reducing the incidence of PMPS,but after 9 and 12 months PVB and combined groups are more effective in decreasing pain with movement than venlafaxine.In addition, the combination of venlafaxine and PVB (group 3) had a similar effect as PVB (group2) with no obvious effect for this combination.More further studies could be conducted.
\end{abstract}

Keywords:Postmastectomy pain syndrome, radical mastectomy, preemptive analgesia, venlafaxine, paravertebral block.

Corresponding author: Reham M. Aamer

Tel:01222522148 .

Received: 1 October 2015

Email:rm.aamer@yahoo.com.

\section{INTRODUCTION}

B reast cancer is the most frequent neoplastic tumor in women, and surgical treatment by modified radical mastectomy or lumpectomy with axillary node dissection is indicated in most patients ${ }^{[1]}$.Postmastectomy pain syndrome (PMPS) is a type of chronic neuropathic pain disorder that can occurs following breast cancer procedures, it is caused by direct nerve injury during breast cancer operation or from subsequent formation of a traumatic neuroma or scar tissue .The pain is typically localized to the anterior /lateral chest wall, axilla and/or
Accepted: 25 October 2015 medial upper arm and persisting more than 3 months after surgery with the characteristic features of neuropathic pain such as burning, tingling, stabbing pain and hyperesthesia ${ }^{[2]}$. The incidence of PMPS is high $(20-57 \%)$ enough to warrant more attention to this syndrome ${ }^{[3]}$. The intensity of acute postoperative pain, the type of operation, involvement of regional lymph nodes, and radiotherapy have been considered the most important treatment-related factors predisposing to chronic pain in patients with breast cancer ${ }^{[4]}$. This chronic pain can be severe enough to cause long term disabilities 
and interferes with patient mood, sleep and performance of daily activities leading to shoulder adhesive capsulitis (Frozen shoulder) or complex regional pain syndrome ${ }^{[5]}$. There is evidence that analgesic treatment in advance of surgical trauma (preemptive analgesia) may be more effective in controlling pain than administering analgesic therapy in response to pain after surgery. Preemptive analgesia has been shown to be efficacious in reducing postoperative pain and may be effective in reducing the incidence of certain types of neuropathic pain syndromes ${ }^{[6]}$. Previous studies have evaluated the analgesic efficacy of administering either ibuprofen, mexiletine, gabapentin, venlafaxine, eutectic mixture of local anesthetics (EMLA), and regional analgesia on the incidence of acute and/or chronic pain following breast cancer surgery ${ }^{[7]}$.Venlafaxine hydrochloride is an antidepressant medication that, like tricyclic antidepressant inhibits the neuronal reuptake of both serotonin and norepinephrine. Venlafaxine does not bind to muscariniccholinergic, histaminc, and $\alpha 1$-adrenergic sites, making its side effects less severe than those of tricyclic antidepressant ${ }^{[8]}$.Paravertebral block (PVB) is the technique of injecting local anesthetic adjacent to the thoracic vertebra close to where the spinal nerves emerge from the intervertebral foramina. This results in ipsilateral somatic and sympathetic nerve blockade in multiple contiguous thoracic dermatomes above and below the site of injection. It is effective in treating acute and chronic pain of unilateral origin from the chest and abdomen ${ }^{[9]}$.Previous two studies have demonstrated that perioperative administration of venlafaxine reduced the incidence of PMPS with 6 months follow up $^{[8,10]}$,another study demonstrated that preincisional PVB reduced the incidence of PMPS with 12 months follow up in women having breast cancer surgery ${ }^{[11]}$. The goal of the present study was to compare this analgesic efficacy of venlafaxine, PVB, and combination of them on acute and chronic pain over 12 months following breast cancer surgery to evaluate which has better effect.

\section{Study type}

PATIENTS AND METHODS

Open labelled study randomized study.

After approval by the hospital ethics committee and a written informed consent this study was carried out on sixty eligible patients undergoing radical mastectomy with axillary dissection during the period from January 2013 to September 2014 in Zagazig University Hospitals under supervision of Anesthesia and Surgical ICU Department.Exclusion criteria included ASA physical status more than II, patients taking antidepressant or anticonvulsant medications,nonsteroidal anti-inflammatory drugs or opioid analgesics, history of diabetes or other neuropathic disease, patients with hepatic or renal impairment, allergies for any used drugs, or patient refusal. Inaddition topre existing coagulopathy, anticoagulation therapy, Bloody tape, infection at the site of needle insertion, or kypho scoliosis for paravertebral block.

Preoperative evaluation and preparation of the patients were done the day before surgery,with explanation of the study protocol.The venlafaxine group and combined group received extended release venlafaxine tablet $37.5 \mathrm{mg}$ (Effexor) for 2 weeks starting the night before surgery.On the day of surgery before induction of anesthesia,for PVB group and combined group,Thoracic Paravertebral Block was done with $0.5 \%$ bupivacaine 1.5 $\mathrm{mg} / \mathrm{kg}$ at $\mathrm{T} 3$ level single shot epidural administration (as indicated by loss of resistance technique).

A standard anesthetic technique was utilized.After preoxygenation via oxygen mask for 3 maximum breath's capacities,anesthesia was induced with intravenous propofol $2 \mathrm{mg} / \mathrm{kg}$, fentanyl1$2 \mu \mathrm{g} / \mathrm{kg}$,rocuronium $\quad 0.6 \mathrm{mg} / \mathrm{kg}$ or cisatracurium $0.15 \mathrm{mg} / \mathrm{kg}$, and a suitable cuffed oral Endotracheal Tube (ETT) was inserted.Anesthesia was maintained with $1 \%$ to $2 \%$ isoflurane, and incremental rocuronium or cisatracurium doses were repeated to maintain neuromuscular block. At the end of surgery,neuromuscular block was antagonized (fixed time based) with intravenous neostigmine $2.5 \mathrm{mg}$ and atropine $1 \mathrm{mg}$. 
After tracheal extubation, patients were transferred to the recovery room. When patients complained of pain in the recovery room, they were received a titrated dose of IV morphine ( $2 \mathrm{mg}$ bolus at $5 \mathrm{~min}$ intervals) until the VAS score was less than or equal to 3 , and then IV morphine $20-50 \mu \mathrm{g} / \mathrm{kg}$ was given as necessary to relieve severe pain, rated by using VAS score greater than 3 for the first 24 hours after surgery, with recording of the total morphine consumption in the first 24 hours.Then, acetaminophen (500 mg tablets) 1tablet every 6 hours and/ or ibuprofen $(10 \mathrm{mg} /$ $\mathrm{kg}$ every 8 hours) tablets from the second to the tenth postoperative day.

Heart rate(beat/min) and blood pressure $(\mathrm{mmHg}) \quad$ were monitored

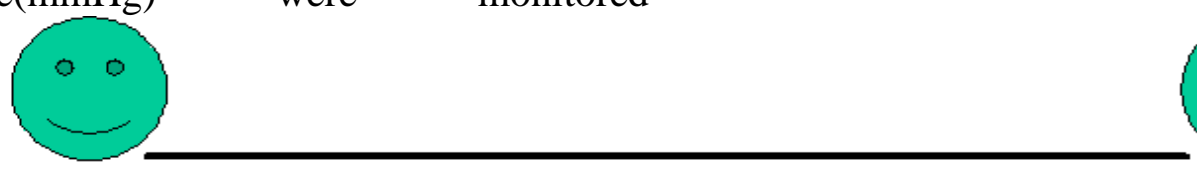

No pain perioperative with recording of the readings preoperative(baseline), after skin incision, and after emergence, monitoring of any complications related to PVB as hypotension, pneumothorax, and dural puncture was done and recorded.

Postoperative pain scores were recorded utilizing a visual analog scale (VAS) pain score from $0-10 ; 0$ representing no pain and 10 representing the worst imaginable pain. Pain scores were recorded at rest and with movement (arm abduction to $90^{\circ}$ ) at 0 hour (after full recovery of the patient), 6, 12, and 24 hours postoperative and then at 1, 3, 6, 9, and 12 months.

2

3

45

\section{At 1, 3, 6, 9 and 12 months} postoperatively, patients were invited and questioned about their current condition regarding pain during rest and motion-related pain using the visual analog scale (VAS) $(0-$ 10 ), if the patient had pain at the time of the interview, she was asked about the various types of pain (sharp, burning, throbbing,tender or pricking pain).Patients were asked whether they had received chemotherapy or radiotherapy and evaluated for presence of edema(Edema was defined as the circumference of the arm on the operative side at least $2 \mathrm{~cm}$ greater than the preoperative circumference).In addition, the patients that had received venlafaxine were asked about any side effects from the drug e.g. headache, nausea, insomnia, dizziness, and decreased appetite, in the first interview. Patients who reported pain symptoms related to the breast operation during the interviews were referred to pain clinic of the hospital to receive regimens of treatment and to be followed up.

\section{Worst pain} ever

$\begin{array}{lllll}6 & 7 & 8 & 9 & 10\end{array}$

\section{Sample size calculation}

Power analysis was performed using Student's t-test for independent samples on mean of VAS score because it was the main outcome variable in the present study. A pilot study was done for 1 month before starting this study because there are no available data in the literature for comparison between venlafaxine and paravertebral block. The results of the pilot study showed that at 24 hour postoperatively, VAS score with movement was $3.12 \pm 1.12$ in patients received perioperative venlafaxine while was $2.14 \pm 1.04$ in patients received perioperative paravertebral block. Taking power 0.8 and alpha error 0.05 , a minimum sample size of 20 patients was calculated for each group. We add another group of 20 patients will receive combination of both techniques of pain control. (MedCalc 13 for windows, MedCalc Software bvba, Ostend, Belgium).

\section{Sampling}

In Zagazig university hospital during years 2011-2012, 256 female underwent modified radical mastectomy. So our target population 
was 256 patients. We plan to do sampling using systemic random sample method as this method, doesn't necessitate presence of sample frame. We calculate K interval, It was 4.2, approximated to 4, so we will include one female out of every 4 females underwent modified radical mastectomy in Zagazig university hospital during period from January 2013 to September 2014. By physical random method we select the first female to be included in the study then we select every $4^{\text {th }}$ female. During the study period, 276 female underwent modified radical mastectomy. 19 patients was founded to be ineligible was excluded and replaced. Dropout occur in 16 patients and also was replaced.

Allocation between the study arms
Allocation of subject in one arm of study was done by using physical method (rolls of dice): $1 \& 2$ for group $1,3 \& 4$ for group $2,5 \& 6$ for group 3, until one group is completed, at that time subjects will randomly allocated between the other two group using coin, head for one group and tail for the other, also until one group is completed, after that all randomly selected subjects will automatically allocated to the remained group.

\section{STATISTICAL ANALYSIS}

All data were analyzed using SPSS 18.0 for windows. One-Way ANOVA,Kruskal-Wallis $\mathrm{H}(\mathrm{KW})$ test, Post-hoc LSD or Games-Howell tests, and Chi-square $(\chi 2)$ test were used. $\mathrm{P}<$ 0.05 was considered statistically significant, $P$ $<0.01$ was considered highly statistically significant.

Flow Chart of the study

\section{RESULTS}

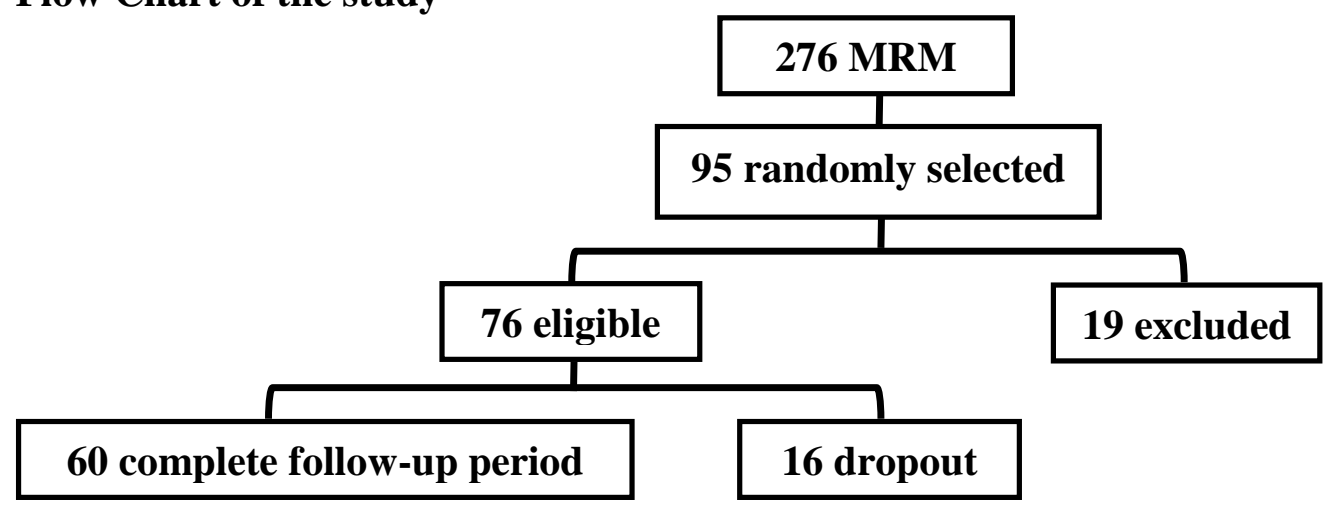

The venlafaxine group (Group 1), paravertebral block (PVB) group (Groups 2) and combined group (receive both venlafaxine and PVB) (Group 3) were similar

with regard to age, body weight, and height. There was no significant difference between groups regarding duration of surgery (Table1).

Table (1):Demographic characteristics of the three studied groups.

\begin{tabular}{|c|c|c|c|c|}
\hline Demographic characteristics & $\begin{array}{l}\text { Group I } \\
(\mathrm{N}=20)\end{array}$ & $\begin{array}{c}\text { Group II } \\
(\mathrm{N}=20)\end{array}$ & $\begin{array}{c}\text { Group III } \\
(\mathrm{N}=20)\end{array}$ & $\mathrm{p}$-value \\
\hline Age (years) & $45.23 \pm 5.32$ & $40.15 \pm 7.21$ & $43.12 \pm 8.23$ & \\
\hline Weight (Kg) & $80.12 \pm 14.28$ & $84.25 \pm 10.43$ & $81.28 \pm 12.61$ & \\
\hline Height $(\mathrm{cm})$ & $164.18 \pm 4.93$ & $160.22 \pm 7.87$ & $161.44 \pm 7.27$ & 161 \\
\hline Duration of surgery (min) & $120.25 \pm 19.87$ & $108.34 \pm 15.42$ & $109.76 \pm 19.85$ & 0.097 \\
\hline \multicolumn{2}{|c|}{$\begin{array}{ll}\text { Data were expressed as mean } \pm \mathrm{SD} \text {, one way } \\
\text { ANOVA was used. } \\
\quad \text { in the preoperative period there were no } \\
\text { significant differences in the heart rate and } \\
\text { mean blood pressure between the three } \\
\text { studied groups, but intraoperative after skin }\end{array}$} & \multicolumn{3}{|c|}{$\begin{array}{l}\text { Incision and after emergence there were } \\
\text { significant increases in the heart rate and } \\
\text { mean blood pressure ( } \mathrm{p}<0.001 \text { ) inpatients of } \\
\text { venlafaxine group (group 1) compared to } \\
\text { hose of PVB group(group 2)and combined } \\
\text { group(group 3) (Table 2). }\end{array}$} \\
\hline
\end{tabular}


Table (2): Comparison of heart rate (beat/min) and mean blood pressure ( $\mathrm{mmHg}$ ) between the three studied groups at preoperative, after skin incision, and after emergence

\begin{tabular}{lccccc}
\hline & $\begin{array}{c}\text { Group I } \\
(\mathrm{N}=20) \\
\text { Mean } \pm \mathrm{SD}\end{array}$ & $\begin{array}{c}\text { Group II } \\
(\mathrm{N}=20) \\
\text { Mean } \pm \mathrm{SD}\end{array}$ & $\begin{array}{c}\text { Group III } \\
(\mathrm{N}=20) \\
\text { Mean } \pm \text { SD }\end{array}$ & Test & $\begin{array}{c}\text { p- } \\
\text { value } \\
\text { Vital signs }\end{array}$ \\
\hline Heart rate (beat/min)
\end{tabular}

data are expressed as mean \pm SD

and compared by one way ANOVA test

**highly significant

The VAS scores were significantly higher $(\mathrm{p}<0.001)$ in venlafaxine group versus PVB and combined groups in the $1^{\text {st }} 24$ hours (Table 3 ).

Table (3): VAS scores comparison between the three studied groups for pain during rest and movement.

\begin{tabular}{|c|c|c|c|c|}
\hline VAS score & $\begin{array}{r}\text { Group I } \\
(\mathrm{N}=20)\end{array}$ & $\begin{array}{c}\text { Group II } \\
(\mathrm{N}=20)\end{array}$ & $\begin{array}{l}\text { Group III } \\
(\mathrm{N}=20)\end{array}$ & p-value \\
\hline Pain during rest at $0 \mathrm{~h}$ & $5.5(3-9)^{* *}$ & $1(0-4)$ & $1(0-3)$ & $<0.001$ \\
\hline Pain with movement at $0 \mathrm{~h}$ & $6.5(4-9)^{* *}$ & $1(0-5)$ & $1(0-4)$ & $<0.001$ \\
\hline Pain during rest at $6 \mathrm{~h}$ & $4(2-6) * *$ & $1(0-4)$ & $1(0-3)$ & $<0.001$ \\
\hline Pain with movement at $6 \mathrm{~h}$ & $5(3-7) * *$ & $1(0-5)$ & $1(0-4)$ & $<0.001$ \\
\hline Pain during rest at $12 \mathrm{~h}$ & $4(2-5) * *$ & $1(0-3)$ & $2(0-3)$ & $<0.001$ \\
\hline Pain with movement at $12 \mathrm{~h}$ & $4(2-6) * *$ & $1(0-5)$ & $2(0-4)$ & $<0.001$ \\
\hline Pain during rest at $24 \mathrm{~h}$ & $3(2-5) * *$ & $1(0-4)$ & $2(0-4)$ & $<0.001$ \\
\hline Pain with movement at $24 \mathrm{~h}$ & $3(1-5) * *$ & $2(0-5)$ & $2(0-5)$ & $<0.001$ \\
\hline Pain during rest at 1 mon & $1.5(0-5)$ & $1(0-5)$ & $1(0-4)$ & 0.532 \\
\hline Pain with movement at 1 mon & $3(0-6)$ & $2(0-6)$ & $2(0-6)$ & 0.370 \\
\hline Pain during rest at 3 mon & $1(0-5)$ & $1(0-4)$ & $1(0-5)$ & 0.874 \\
\hline Pain with movement at 3 mon & $2(0-6)$ & $2(0-5)$ & $1.5(0-6)$ & 0.403 \\
\hline Pain during rest at 6 mon & $1(0-5)$ & $1(0-4)$ & $1(0-4)$ & 0.778 \\
\hline Pain with movement at 6 mon & $2(0-5)$ & $2(0-5)$ & $2(0-5)$ & 0.475 \\
\hline Pain during rest at 9 mon & $1(0-5)$ & $1(0-3)$ & $1(0-3)$ & 0.643 \\
\hline Pain with movement at 9 mon & $2(0-5)^{*}$ & $1(0-5)$ & $0.5(0-5)$ & 0.011 \\
\hline Pain during rest at 12 mon & $1(0-4)$ & $0(0-2)$ & $1(0-2)$ & 0.236 \\
\hline Pain with movement at 12 mon & $2(0-5)^{*}$ & $0(0-5)$ & $0(0-5)$ & 0.016 \\
\hline
\end{tabular}

Data were expressed as median (range), Kraskall Wallis H test was used.

*significant $\quad * *$ highly significant

At 1, 3, and 6 months postoperative, there were no significant differences in VAS scores between the three groups either during rest or with movement. At 9 and 12 months however, the VAS scores during rest did not significantly differ between the three groups, the scores with movement were significantly reduced $(\mathrm{P}<0.01$ at 9 month and $\mathrm{P}<0.01$ at 12 month) in PVB and combined groups in comparison with venlafaxine group (Table 3 ).

The total morphine consumption in the $1^{\text {st }} 24$ hours were significantly reduced in PVB group (group 2) and combined group (group 3) $\quad(\mathrm{P}<0.001) \quad$ compared with venlafaxine group (group 1) (Table 4). 
Table (4): Total analgesic dose (morphine mg/day) comparison between the three studied groups in the first 24 hours postoperative.

Total analgesic dose

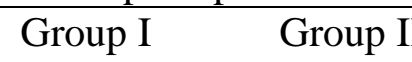

Morphine (mg/day)

Group I

$(\mathrm{N}=20)$

$(\mathrm{N}=20)$

Group III

$22 * *(18-25) \quad 10(8-12)$

$(\mathrm{N}=20)$

$\mathrm{p}$-value

Data were expressed as median (range), Kraskall Wallis H test was used.

**highly significant

No significant differences were noted between the studied groups as regard number of patients treated with chemotherapy and/or radiotherapy, or the incidence of postoperative arm edema (Table 5).

Table (5): Comparison of postoperative chemotherapy, radiotherapy and incidence of postoperative edema in the three studied groups.

\begin{tabular}{lcccc}
\hline Characteristics of chronic pain & $\begin{array}{c}\text { Group I } \\
(\mathrm{N}=20)\end{array}$ & $\begin{array}{c}\text { Group II } \\
(\mathrm{N}=20)\end{array}$ & $\begin{array}{c}\text { Group III } \\
(\mathrm{N}=20)\end{array}$ & p-value \\
\hline Chemotherapy & 15 & 18 & 16 & 0.459 \\
\hline Radiotherapy & 10 & 11 & 10 & 0.935 \\
\hline Arm edema & 11 & 10 & 13 & 0.622 \\
\hline
\end{tabular}

Data were expressed as actual number, Chi-square test was used.

Data in (Table 6) showed no difference between study groups in the main characteristics of chronic pain.

Table (6): characteristics of chronic pain between the three studied groups during $12 \mathrm{months}$ postoperatively.

\begin{tabular}{lcccc}
\hline \multicolumn{1}{c}{ Characteristics of chronic pain } & $\begin{array}{c}\text { Group I } \\
(\mathrm{N}=20)\end{array}$ & $\begin{array}{c}\text { Group II } \\
(\mathrm{N}=20)\end{array}$ & $\begin{array}{c}\text { Group III } \\
(\mathrm{N}=20)\end{array}$ & p-value \\
\hline Pricking & 3 & 1 & 0 & 0.153 \\
\hline Tender & 2 & 0 & 0 & 0.126 \\
\hline Burning & 0 & 2 & 2 & 0.343 \\
\hline
\end{tabular}

Data were expressed as actual number, Chi-square test was used.

There was no significant difference regarding complications among the groups (Table 7).

Table (7): The recorded complications with venlafaxine and PVB in the three studied groups.

\begin{tabular}{lcccc}
\hline Complications & $\begin{array}{c}\text { Group I } \\
(\mathrm{N}=20)\end{array}$ & $\begin{array}{c}\text { Group II } \\
(\mathrm{N}=20)\end{array}$ & $\begin{array}{c}\text { Group III } \\
(\mathrm{N}=20)\end{array}$ & $\begin{array}{c}\text { p-value } \\
(\text { Sig. })\end{array}$ \\
\hline No complications & 14 & 17 & 16 & 0.503 \\
\hline Complications & 6 & 3 & 4 & \\
\hline Nausea & 3 & 0 & 2 & 0.217 \\
\hline Dizziness & 2 & 0 & 0 & 0.126 \\
\hline Headache & 1 & 0 & 0 & 0.362 \\
\hline Accidental vascular puncture & 0 & 1 & 0 & 0.362 \\
\hline Hypotension & 0 & 2 & 1 & 0.349 \\
\hline Epidural spread & 0 & 0 & 1 & 0.362 \\
\hline
\end{tabular}

Data were expressed as actual number, Chi-square test was used.

\section{DISCUSSION}

The current study demonstrated that perioperative administration of venlafaxine extended release $37.5 \mathrm{mg}$ for 2 weeks beginning the night before surgery (group 1) has no immediate effect on acute postoperative pain and analgesic use,in addition to increased HR and MAP after skin incision and after emergence, which was significantly different from preincisional PVB 
with $0.5 \%$ bupivacaine $1.5 \mathrm{mg} / \mathrm{kg}$ at $\mathrm{T} 3$ before general anaesthesia (Groups 2 and 3) that provided immediate postoperative analgesia evidenced by significant lower VAS scores and reduced consumption of intravenous opioid in the first 24 hour. With the follow up interviews at 1 and 6 months postoperatively we found that there were no significant differences between the groups regarding the pain scores by (VAS) either during rest or with movement .At 9 and 12 months interviews our results became different, whereas a significant decrease was occurred in the VAS scores for pain with movement in both PVB group and combined group compared to the venlafaxine group, however no significant differences in the scores between the groups for pain during rest.no significant differences were shown between the studied groups as regard postoperative complications, prevalence of postoperative edema and chronic pain characteristics.

These results may be attributed to the mechanism of action of PVB. First, in the thoracic paravertebral space (TPVS), the local anesthetics spread laterally along the intercostal nerves and affect the sympathetic chain, thus produced a high degree of afferent blockade $^{[12]}$. Second, the spinal nerves in the TPVS are segmented into small bundles devoid of fascial sheath, this render them extremely susceptible to the injected local anesthetics. Third, epidural spread may contribute to the extension of thoracic paravertebral blockade ${ }^{[13]}$. PVB have shown to reduce chronic pain after thoracic and breast surgery. This is possibly because of intense block of both the sympathetic and somatic nerves, preventing sensitization of the central nervous system and N-methyl-Daspartate receptor "wind up" ${ }^{\text {[14] }}$. Central sensitization is a stepwise permanent modification of spinal pain pathways involving protein synthesis and permenant modification of synaptic strength. Central sensitization can lead to hyperalgesia and chronic pain ${ }^{[15]}$.

Regarding venlafaxine, similar studies were done by Reuben et al. ${ }^{[10]}$ and Amr and Yousef ${ }^{[8]}$ who reported in their studies that venlafaxine had no immediate effect on acute postoperative pain and analgesic use,while significantly reduced the incidence of PMPS after follow up of the patients for only 6 months postoperatively and explained this as it may have been the result of reducing adrenergic nociceptive pathways responsible for the development of central sensitization and neuropathic pain.

Animal experiments have shown venlafaxine to have an analgesic effect that is mediated mainly via adrenergic mechanisms, and its preemptive administration was an effective technique in reducing hyperalgesia in the rat model of neuropathic pain ${ }^{[16]}$.

Our results about PVB on acute postoperative pain are consistent with the result of Dabbagh and Elyasis and [17] Boughey et al. ${ }^{[18]}$ who evaluated the effect of PVB on pain scores and morphine consumption after mastectomy and reported that PVB significantly decreased postoperative pain and analgesic use without recorded

complications.However,Buckenmaier et al. ${ }^{[19]}$ and Ibarra et al. ${ }^{[20]}$ are inconsistent with our results as they observed in their studies that thoracic PVB had no significant effect on acute postoperative pain when compared to general anesthesia

Regarding the effect of PVB on chronic pain a similar study was done by Kairaluoma et al. ${ }^{[11]}$ who reported that preincisional PVB significantly decreased the prevalence and the severity of pain in patients with modified radical mastectomy after follow up for 12 months, another study was done by Ibarra et al. ${ }^{[20]}$ who recorded the same finding but with follow up of the patients for only 4 to 5 months postoperatively.

However the study of Karmakar et al. ${ }^{[21]}$ is somewhat different as they evaluated the efficacy of thoracic PVB on the incidence of chronic pain after modified radical mastectomy and they observed no significant difference in the chronic pain incidence at 3 and 6 months postoperatively.

Radiotherapy used in the treatment of breast carcinoma may be implicated in PMPS, this may be as a result of radiation-associated neuromodulatory changes at the peripheral neuronal level ${ }^{[22]}$. 
In our study we observed in the follow up interviews that all the patients presented with pain in the 3 groups received radioatherapy. This result is supported byTasmuth et al. ${ }^{[23]}$ and Kairaluoma et al. ${ }^{[11]}$ who reported that radiation treatment to the breast and/or axilla was associated with increased risk of chronic pain compared with postoperative patients not receiving radiation therapy.Another recent study was done by Johansen et al. ${ }^{[24]}$ who observed the relationship between radiotherapy and arm/shoulder morbidity in breast cancer patients, he reported that radiotherapy results in long-term arm/shoulder morbidity and the dose should be reduced to minimize this risk.This confirms radiotherapy as a predisposing factor for chronic pain.

\section{Limitation of the study}

The current study is limited due to the long duration of pain assessment with the consequences of some difficulties in communication with the patients. In addition the pain assessment was done by VAS score which is highly sensitive to clinical changes but it is mainly subjective and so depends on the degree of culture and cooperation of the patient to the study.

\section{RECOMMENDATIONS}

Further studies are needed including larger sample size, and using a number of assessment tools that attempt to measure multiple aspects of the pain experience.

\section{CONCLUSION}

The result of the present study concluded that preincisional PVB either alone or combined with venlafaxine provides good acute postoperative pain relief with reduction of morphine consumption in the $1^{\text {st }} 24$ hours than venlafaxine. The efficacy of venlafaxine, PVB, or combination of them are similar after 6 months in reducing chronic pain, but after 9 and 12 months PVB and combined groups are more effective in decreasing pain with movement than venlafaxine.

\section{REFERENCES}

1. Couceiro TC, Menezes TC and Valenca MM. Post-mastectomy pain. The magnitude of the problem.RevistaBrasileira de Anestesiologia.2009;59 (3):358-65.

2. Shen J. Clinical manifestations and diagnosis of postmastectomy pain
syndrome.WWW. UpToDate.com. .Apr 2015. last updated Mar 02, 2015.

3. Visnjevac $O$ and Matson $B$. Postmastectomy pain syndrome: an unrecognized annual billion dollar national financial burden. The Journal of Pain 2013;14:33.

4. Jung BF, Ahrendt GM, Oaklander AL and Dworkin RH. Neuropathic pain following breast cancer surgery: proposed classification and research update. Pain 2003; 104:1-13.

5. Macdonald L, Bruce $J$ and Scott NW. Long-term follow-up of breast cancer survivors with post-mastectomy pain syndrome. B.J. Cancer 2005;92:225-230.

6. Sentu“rk M, Ozcan PE and Talu GK.The effects of three different analgesia techniques on long term postthoracotomy pain. Anesth.Analg.2002;94:21-25.

7. Reuben SS. Preventing postmastectomy pain syndrome. International Researsh Foundation for RSD/CRPS 2009.

8. Amr YM and Yousef AA. Evaluation of Efficacy of the Perioperative Administration of Venlafaxine or Gabapentin on Acute and Chronic Postmastectomy Pain. Clin. J. Pain 2010;26:381-385.

9. Karmakar MKT. Thoracic paravertebral block.Anesthesiology 2001;95:771-80.

10. Reuben SS, Makari-Judson $G$ and Lurie SD. Evaluation of efficacy of perioperative administration of venlafaxine XR in the prevention of postmastectomy pain syndrome. Journal of Pain and Symptom Management 2004;27:131-7.

11. Kairaluoma PM, Bachmann MS, Rosenberg PH and Pere PJ. Preincisional Paravertebral Block Reduces the Prevalence of Chronic Pain After Breast Surgery. Anesth.Analg.2006;103:703-8.

12. Eid HEA. Paravertebral block: An overview.CurrAnesth\&Crit Care 2009;20:65-70.

13. Purcell-Jones G, Pither $\mathrm{CE}$ and Justins DM. Paravertebra somatic nerve block: a clinical, radiological, and computed tomographic study in chronic patients. Anesth. Analg.1989;68:32-9.

14. Tighe SQM, Greene MD and Rajadurai N. Paravertebral block.Continuing Education in Anaesthesia. Critical Care \& Pain J.2010;10 (5):133-7.

15. Andreae ${ }^{1 *}$ MH, Andreae ${ }^{2} \mathrm{DA}$. Regional anaesthesia to prevent chronic pain after 
surgery: a Cochrane systematic review and meta-analysis. British Journal of Anaesthesia 2013;111(5):711-20.

16. Lang E, Hord AH and Denson $D$. Venflaxine hydrochloride (Effexor?) relieves thermal hyperalgesia in rats with an experimental mononeuropathy. Pain 1996; 68:151-5.

17. Dabbagh A, Elyasi $H$. The role of paravertebral block in decreasing postoperative pain in elective breast surgeries. Med SciMonit.2007;13:CR464-7.

18. Boughey JC, Goravanchi F, Parris RN,Kee SS, Kowalski AM, Frenzel JC,et al. Prospective randomized trial of paravertebral block for patients undergoing breast cancer surgery. Am J Surg.2009;198:720-5.

19. Buckenmaier $\mathrm{CC}$, Kwon KH and Howard RS. Double-blinded, placebocontrolled, prospective randomized trial evaluating the efficacy of paravertebral block with and without continuous paravertebral block analgesia in outpatient breast cancer surgery. Pain Med.2010;11:790-9.
20. Ibarra MM, S-Carralero GC, Vicente GU, Cuartero del Pozo A, LópezRincón $\mathbf{R}$ and Fajardo del Castillo MJ. Chronic postoperative pain after general anesthesia with or without a single-dose preincisional paravertebral nerve block in radical breast cancer surgery. Rev. Esp. Anestesiol. Reanim.2011;58 (5): 290-4.

21. Karmakar MK, Samy W, Li JW, Lee A, Chan WC, Chen PP,et al. Thoracic paravertebral block and its effects on chronic pain and health-related quality of life after modified radical mastectomy. Reg. Anesth. Pain Med.2014;39 (4): 289-98.

22. Chang SH, Mehta V, and Langford RM. Acute and chronic pain following breast surgery. Acute Pain J.2009;11: 1-14.

23. Tasmuth T, Kataja M, and Blomqvist $C$. Treatment-related factors predisposing to chronic pain in patients with breast cancera multivariate approach. ActaOncol.1997; 36:625

24. Johansen S, Fosså K, Nesvold IL, Malinen E, and Fosså SD. Arm and shoulder morbidity following surgery and radiotherapy for breast cancer.ActaOncol_2014;53(4):521-9. 